\title{
Monitoring and optimising outcomes of survivors of critical illness
}

Leanne M Aitken, RN, PhD, FACN, FAAN, FACCCN

Professor of Critical Care Nursing, NHMRC Centre of Research Excellence in Nursing,

Centre for Health Practice Innovation, Griffith Health Institute, Griffith University, Brisbane, Australia and Intensive Care Unit, Princess Alexandra Hospital, Woolloongabba, Australia AND

Professor of Nursing, School of Health Sciences, City University London, United Kingdom

Andrea P. Marshall, RN, PhD, FACN, FACCCN

Professor of Acute and Complex Nursing, NHMRC Centre of Research Excellence in

Nursing, Centre for Health Practice Innovation, Griffith Health Institute, Griffith University,

Gold Coast, Australia and Gold Coast University Hospital, Australia

\section{Corresponding Author:}

Leanne M Aitken

Email: 1.aitken@griffith.edu.au

Phone: +61 731767256

Postal Address:

School of Nursing \& Midwifery

Griffith University, Nathan Campus

170 Kessels Road

Nathan QLD 4111

Australia 


\begin{abstract}
Recovery after critical illness can be protracted and challenging. Compromise of physical, psychological, cognitive and social function is experienced by some patients and may persist for a number of years. Measurement of recovery outcomes at regular time points throughout the critical illness and recovery pathway is necessary to identify problems and guide selection of interventions to prevent, minimise or overcome that compromise. Optimisation of factors that enhance recovery, such as sleep, nutrition and memories of intensive care, will also assist with promotion of recovery.
\end{abstract}

Effective assessment of recovery requires integration of assessment of outcomes into routine clinical practice by all members of the interdisciplinary team. There must be agreement of appropriate measures and measurement timeframes alongside relevant education and training to ensure optimal assessment and use of the information gained. Assessment outcomes need to be communicated to interdisciplinary team members across the critical illness and recovery trajectory. Adequate resourcing for both the assessment activities and subsequent care is essential to improve patient outcomes after critical illness.

\title{
Keywords
}

Intensive care, critically ill, recovery, patient outcome assessment, 


\section{Implications for clinical practice}

- Measurement of all aspects of recovery at multiple time points after critical illness will enable individualised support programmes to be delivered

- Education and training of relevant health care personnel is necessary to ensure optimal assessment and use of information

- Routine practice should incorporate optimisation of factors that enhance recovery, for example sleep, nutrition and psychological status 


\section{Introduction}

There is widespread evidence that survivors of critical illness experience multi-dimensional compromise during their recovery (Needham et al., 2012). This recovery extends for weeks to years, with the recovery trajectory being different for each patient. Pre-existing health problems, psychological status and social circumstances all influence the recovery trajectory and are somewhat unique for each patient. The uniqueness of each patient's situation and the challenges they face means that different interventions may be required to meet individual goals.

Determining goals for each patient requires comprehensive assessment that incorporates the wishes of the patient and their family. Knowing the patient's pre-illness function and status will also inform realistic goals and interventions during recovery. Because critical illness is unexpected, accurately measuring baseline function and status is not possible and needs to be estimated from information provided by the family during the critical illness or the patient during recovery. A comprehensive, systematic approach incorporating all aspects of physical, psychological and social function should be used to elicit information to estimate baseline function. Inclusion of measures that incorporate pre-illness status, for example the Charlson Comorbidity Index (Charlson et al., 1987) and a measure of frailty, should be considered. Although both comorbidities and frailty overlap with function, additional understanding and detail is contributed by considering each of the concepts independently (Fried et al., 2001). No measure of frailty has been validated for use in the critical care population, although a trauma specific index has been developed (Joseph et al., 2014).

In recent years there has been considerable work undertaken to develop and refine interventions to promote recovery from critical illness. Evaluating the effectiveness of these 
interventions is dependent on measurement of relevant components of recovery and selecting the most appropriate times to undertake assessment. Measurement of functional outcomes during critical illness, for which there are several review papers available (Hough 2013), often takes priority but measurement of recovery should not be limited to physical or functional aspects of health. The focus of this paper is examination and optimisation of all aspects of recovery following critical illness.

Integral to patient recovery is the health and well-being of family members. Although many of the physical, functional and cognitive issues do not affect family members, there is growing evidence of the psychological and social issues experienced by both patients and their families (Lemiale et al., 2010, Buckley et al., 2012). The impact on family members has not been incorporated into this paper although this is an important aspect of recovery from critical illness for which many of the same outcome measures can be used. It is also important to explore how family involvement can be incorporated into effective strategies for improving the outcomes of patients following critical illness. Early reports of successful strategies involving family members to deliver or contribute to patient recovery focused interventions include both mobilisation (Rukstele and Gagnon 2013) and nutrition (personal communication - Prof Daren K Heyland, Queen's University, Kingston, Ontario, Canada).

\section{What outcomes should we monitor in survivors of critical illness?}

In its simplest form, measurement of outcome has involved monitoring mortality in survivors of critical illness, as well as other uni-dimensional characteristics such as organ failure and readmission to hospital. Expansion of the concept of outcome to include patient centred outcomes such as physical function and quality of life was seen in the 1990s, and more recently has been extended to include psychological, cognitive and social function. Use of 
strategies to measure and improve these aspects of recovery in survivors of critical illness is now considered an essential component of critical care practice.

Few instruments to measure patient outcomes have been developed or validated specifically for use in the critical care population. Instead we have adopted instruments developed for general use or for use in other patient populations (Table 1). A detailed review of instruments to measure physical function and quality of life is also available (Elliott et al., 2011).

\section{Insert Table 1 about here}

The benefits of adoption of generic instruments to measure patient outcome are two-fold. First, the use of generic instruments can reduce the time and cost incurred in developing an instrument. Using a generic instrument that has been used to report data for the non-critically ill patient populations also allows us to compare outcomes across groups of acute and critically ill patients. However, the use of generic instruments is not without disadvantages. For example, a certain level of cognitive function may be required to understand the questions posed and formulate a response, a process that may be challenging for some patients with impaired cognitive function. Determining cognitive function it essential before using any instrument as cognitive impairment can persist for many months following critical illness (Pandharipande et al., 2013). Also to be considered are the outcomes of interest. For example, memories of the critical care experience can be unique and generic instruments may be inadequate for their evaluation. Evaluating outcomes following critical illness, particularly when there are multiple outcomes of interest, can become an extensive process which could be potentially burdensome to the recovering critically ill patient. The burden might be more pronounced in the early stages of recovery in hospital than following hospital discharge. 
Consequently selection of the outcomes of greatest importance to a patient might be necessary to ensure targeted evaluation of recovery.

In addition to measuring outcome, it is beneficial to also assess the factors that influence outcome so that we can assist the patient with the most appropriate interventions to promote recovery. Although there is limited evidence regarding which potentially modifiable factors are most influential, and in which patients these apply, some aspects to consider include sleep, memories of intensive care, nutrition and infection prevention. Suggested strategies for measuring these factors are outlined below.

Sleep: There are beginning reports of the important role the quality and quantity of patients' sleep when they go home has on recovery (Orwelius et al., 2008, McKinley et al., 2012) with patients reporting worse quality of life when they have poor sleep. Reliable and valid instruments to measure sleep in critically ill patients are uncommon, although there are more options available as patients recover and are discharged to the ward and then home. The Richards-Campbell Sleep Questionnaire (RCSQ) (Richards et al., 2000) can be used in the awake critical care and acute care population so that strategies to improve sleep can be commenced early in recovery. Once survivors of critical illness are discharged home the Pittsburgh Sleep Quality Index (PSQI) (Buysse et al., 1989), an instrument where sleep quality and patterns are measured on 19 items across a four point scale, is relevant for use. Good internal consistency has been demonstrated and high sensitivity and specificity has been shown for diagnosing good/poor sleepers (Buysse et al., 1989). When poor quality and patterns of sleep are identified, strategies to help improve sleep are warranted and research is encouraged to determine which methods are most effective for improving sleep. 
Memories of intensive care: There is growing evidence that unpleasant or delusional memories after ICU are associated with poor outcomes including psychological distress and lower health related quality of life (Kiekkas et al., 2010, Ringdal et al., 2010). The Intensive Care Experience Questionnaire has been developed specifically for the purpose of measuring patients' recall of their experience in ICU (Rattray et al., 2004) which may facilitate treatment of those with distressing or unpleasant memories. Alternatively, in the future it may be possible to screen for those who are going to have greatest problems with psychological compromise and target early interventions to those patients. Although at this stage no predictive screening instrument has been developed for use in the ICU population, a similar instrument has been developed for use in the injured population (Richmond et al., 2011). Early identification of patients most likely to experience compromise will allow targeting of interventions to prevent or minimise psychological compromise.

Nutritional status: Nutritional status is an important factor in recovery from critical illness. Protein and energy depletion that can occur in critical illness has been associated with poorer functional outcomes for patients including muscle weakness (Vivodtzev et al., 2014), myopathy and polyneuropathy (Hermans et al., 2014). The prevalence of malnutrition is substantial and although a universally accepted approach to determining malnutrition is lacking, it is estimated that $15-60 \%$ of adults might be malnoursished (White et al., 2012). Critically ill patients can present with pre-existing malnutrition or develop malnutrition while in hospital. During the episode of critical illness the risk of malnutrition is increased because of significant metabolic changes occurring in critical illness that result in hypermetabolism and hypercatabolism (Btaiche et al., 2010). As critical illness resolves and patients are extubated and resume oral intake, malnutrition can result because of decreased nutrition 
intake (Peterson et al., 2010). The risk of malnutrition is therefore present throughout the critical illness trajectory and can persist during recovery (Herridge et al., 2003).

Understanding the degree of risk can assist clinicians to assess the consequences of malnutrition and initiate appropriate treatment. There are multiple tools available to assist with nutrition screening and the selection of tools to measure nutrition risk will be influenced by the time point in the patient's recovery trajectory. For example, a nutrition risk assessment specific to critical illness should be used in the intensive care unit (Heyland et al., 2011) while other nutritional risk assessments are better suited to the recovery period (Mueller et al., 2011). Assessing the degree of malnutrition will also require the use of specific measures, such as the use of the Subjective Global Assessment (Fontes et al., 2014). Some nutrition screening and assessment tools have been specifically developed for use in the elderly (Young et al., 2013) who represent a growing proportion of critically ill patients worldwide. Both nutrition screening for risk and assessment for malnutrition are important considerations in a patient's recovery after critical illness, particularly because malnutrition is underrecognised and under-diagnosed in both acute care and community settings (Watterson et al., 2009).

Infection prevention: The prevention of healthcare-associated infections (HAIs) is a priority for health services across the globe. Specific interventions are identified to prevent common infections such as catheter-related urinary tract infection, surgical site infection, clostridium difficile infection, central line associated blood stream infection (CLABSI), and ventilatorassociated pneumonia (VAP) (Yokoe et al., 2014). Of these infections, CLABSI and VAP are the most costly on a per case basis (Zimlichman et al., 2013) and also most likely to be observed in the critically ill patient population. 
There have been significant achievements in reducing HAIs in the intensive care environment and this can be largely attributed to the implementation of evidence-based interventions. For example, the introduction of bundles of care in relation to central line insertion (Tang et al., 2014)and management (Guerin et al., 2010) has resulted in a reduction in the number of infections associated with intravascular devices in the critically ill (Pronovost et al., 2006). Similar impact has been observed with the introduction of ventilator bundles which, when implemented, can result in the reduction of VAP (Zilberberg and Shorr 2011) however the compliance with such bundles is noted to be challenging (Pogorzelska et al., 2011). Effective implementation of prevention strategies (Squires et al., 2014) and monitoring of compliance is necessary to ensure optimal outcomes. Specific interventions aimed at infection prevention in the critically ill are described elsewhere and include broad aspects such as education, accountability, surveillance and hand hygiene as well as site specific considerations (Aitken et al., 2011).

\section{When should we monitor outcomes?}

There is currently a lack of evidence for optimal time points to monitor recovery, with measurement at different time points likely to lead to different judgements about compromise (Lemiale et al., 2010). Outcome assessment is more important for some patients, particularly those who have experienced long-term critical illness (Fletcher et al., 2003), although compromise is not limited only to those with long hospital stays. We know that some patients continue to experience compromise in excess of five years after their critical illness (Kaarlola et al., 2003, Herridge et al., 2011) but many patients consider themselves fully recovered long before this time. While monitoring outcome is important to identify patient problems and 
facilitate planning and delivery of interventions, it is equally important to determine which patients have recovered and are unlikely to benefit from ongoing monitoring.

The optimal time point may depend on which outcome is being measured. The recovery pathway for survivors of critical illness is not uniform across all elements of outcome, with some elements being more compromised or returning to normal levels more rapidly than others, for example physical function may improve more quickly than psychological function (Hofhuis et al., 2008, Berkius et al., 2013).

A comprehensive, systematic and multi-disciplinary approach to assessing outcomes is necessary to support future plans for patient management. The extent to which this currently occurs prior to ICU discharge is unclear, but it is essential for assessment of outcome to begin at this time to provide a baseline for planning and ongoing intervention. Recovery following critical illness extends beyond hospitalisation. In preparation for hospital discharge there is a need to reassess patient outcomes to determine the extent to which the patient has improved (or not) and to communicate this information to those responsible for patient care in the community. Comprehensive physical assessment is frequently undertaken, especially for those patients who are discharged into a subacute or rehabilitation setting. Determining psychological and cognitive compromise, or the need for social support, is more difficult.

Ongoing assessment following hospital discharge can help to identify issues that might, if not addressed, lead to hospital readmission. Follow up of survivors of critical illness after hospital discharge differs within and across health systems. The general practitioner or primary physician is often the primary point of contact. With the breadth of a general practitioner's clinical practice it is likely that a very small percentage of their patients will be 
survivors of critical illness and consequently the general practitioner is unlikely to be familiar with expected recovery pathways or the physical, psychological cognitive or social challenges that the patient might experience.

ICU follow up services are available in some health services but the extent to which these are available worldwide is variable. The influence such systems have on patient outcome is, however, uncertain (Prinjha et al., 2009). Studies of ICU follow-up services frequently describe the sequelae and patient-reported experiences of critical illness but are silent on other important outcomes, such as cognitive function, hospital readmissions and costeffectiveness. Nevertheless, such systems provide a strategy for health care professionals experienced in assessing survivors of critical illness to monitor patients after hospital discharge (De la Cerda 2013).

\section{What does this mean for critical care practice?}

Assessment of outcomes during recovery from critical illness is required for there to be a positive and sustained impact on survivors. Successful implementation of this approach to assessment and subsequent care will require a number of strategies including (i) integration of assessment of outcomes into routine practice; (ii) agreement on appropriate measures of outcome to be used; (iii) agreement on when outcome assessment should occur; (iv) education and training for staff to undertake outcome assessment.

Integration of assessment of outcomes is not yet widely implemented into clinical practice. Such assessment must be integrated into routine practice at various stages such as prior to discharge from each of ICU and the hospital ward, as well as during follow-up through clinics or outpatients. While we believe this approach is fundamental to improving outcomes 
for survivors of critical illness there is also the need for activities to be undertaken by all members of the interdisciplinary team, for the results of these assessments to be effectively communicated to inform care across the critical illness continuum and to ensure adequate resourcing for both assessment and subsequent care; this is likely to optimise the impact relative to the resources invested.

There has been some agreement within the critical care speciality regarding the presence of compromise and the need for improved strategies to improve care and mitigate long-term health problems (Needham et al., 2012). There has also been development in some countries or regions of the principles that should underpin these strategies to improve care (Gosselink et al., 2008, National Institute for Health and Clinical Excellence 2009). Despite this there is not yet international agreement on the most appropriate specific methods and time points to measure patient compromise and intervene effectively.

Additional education and training across a number of disciplines and across clinical contexts including ICU, the hospital, rehabilitation and the community is required. Importantly, the way in which patient management can influence patient recovery into the future needs to be recognised and clinicians should be encouraged to think about recovery beyond discharge from their clinical area.

The nature of the specific outcomes assessment may mean that some disciplines are likely to be better positioned to undertake the assessment and determine optimal interventions than others. However, an interdisciplinary approach to outcome assessment, intervention selection and delivery is necessary to ensure optimal uptake and implementation. Such an approach will benefit from clearly defined roles and responsibilities to maximise use of resources and 
avoid duplication or omission of effective interventions. A critical aspect of the interdisciplinary approach is the communication of the plan as patients transition through the hospital system and into the community as this will ensure continuity and is likely to achieve the best outcomes.

\section{What does this mean for critical care research?}

In regard to many aspects of outcome after critical illness we have a thorough understanding of the extent of the problems that survivors experience. We have identified some of the factors that relate to improving recovery (Rubenfeld 2007), but large scale multi-centre studies with high levels of follow-up are required to effectively identify the factors to which interventions should be targeted if patient outcomes are to be improved. There is also a strong imperative for researchers to move forward from observational work towards the conduct of randomised controlled trials which are the most appropriate study design to determine the effectiveness of interventions to improve all aspects of patient outcome.

An important aspect of evaluating the effectiveness of interventions is determining the optimal time for interventions to be introduced during and following recovery from critical illness. Some interventions need to commence as soon as the patient becomes critically ill, for example strategies for minimising sedation and improving sleep within the ICU. There is evidence that sedation minimisation improves clinical outcomes for critically ill patients (Barr et al., 2013), however we do not yet have evidence of which strategies effectively achieve this aim. Strategies that had early initial support in single settings such as protocol directed sedation (Brook et al., 1999) and daily sedation interruption (Kress et al., 2000) have been shown to not be effective in other settings and may cause harm (Elliott et al., 2006, Bucknall et al., 2008, Mehta et al., 2012). 
Further effective interventions are also required to assist recovery in the later stages of the patient's ICU stay and during hospitalisation after ICU discharge. Potential targets of these interventions include mobilisation and strength, ensuring nutritional adequacy, and optimisation of memory and psychological status. Again, we have limited high quality evidence of effective strategies, although early reports of techniques to improve mobilisation appear promising (Bailey et al., 2007, Burtin et al., 2009, Schweickert et al., 2009, Berney et al., 2012). In addition, studies to develop and test early psychological interventions are beginning (Peris et al., 2011), although sample sizes and methodological rigour is not yet adequate to determine benefit.

It is then vital that we identify how best to assist patients after they leave hospital. Tailoring interventions to individual patient need will be required to ensure optimal use and targeting of resources to those most likely to benefit from the intervention. There is conflicting evidence regarding the benefit of strategies such as a rehabilitation programme or ICU follow-up service for survivors of critical illness, with studies in both Australia and the UK finding no benefit (Cuthbertson et al., 2009, Elliott et al., 2011), while one UK study testing the effect of a self-help rehabilitation manual identified improvement in recovery (Jones et al., 2003). Similarly, much discussion and early investigation has focused on the provision of diaries after intensive care, although at this stage the body of work has significant limitations precluding implementation as routine clinical practice (Aitken et al., 2013).

Although usually not measured on an individual basis, assessment of cost-effectiveness should be integrated into research endeavours. Given the significant expense of critical care to the individual, the health care system and society, it is vital that we assess the cost 
effectiveness of our interventions and how to achieve maximum benefit for the patient and their family with minimal cost to all.

\section{Conclusion}

Survivors of critical illness experience multi-dimensional compromise during their recovery.

Ongoing measurement of outcomes is essential to optimise the delivery of interventions to those who most need support. Outcome assessment should commence in the ICU and continue throughout the ward stay and into the community as a routine component of clinical practice. There is agreement that physical, psychological, cognitive and social function and quality of life are important, although there is a lack of agreement as to the precise instruments that should be used to assess these domains, or the time points when assessment should occur. Identification of compromise is the first step in a process that must include delivery of interventions to overcome compromise. Research to identify effective interventions to prevent or minimise compromise and improve recovery are urgently required. 


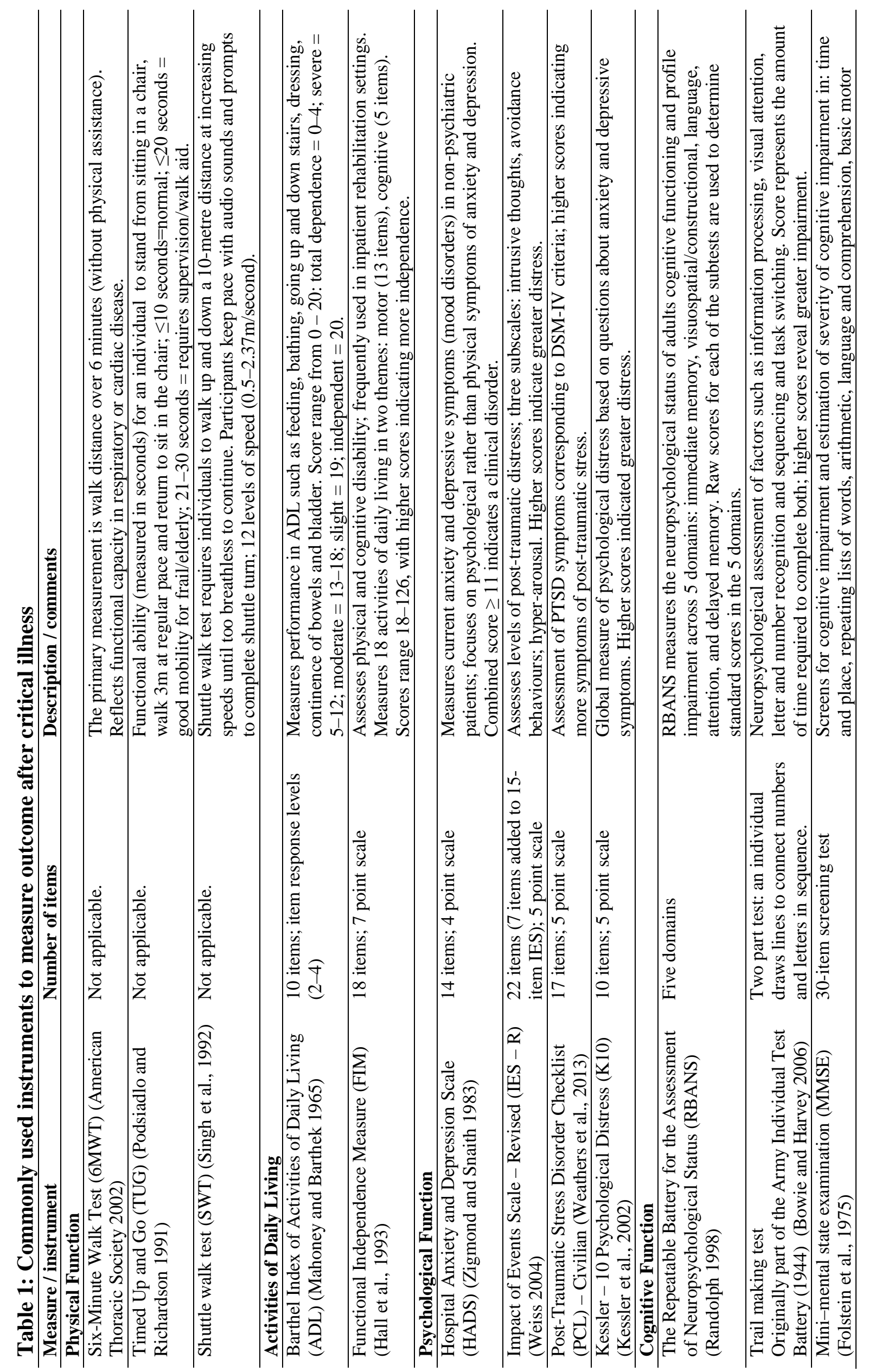




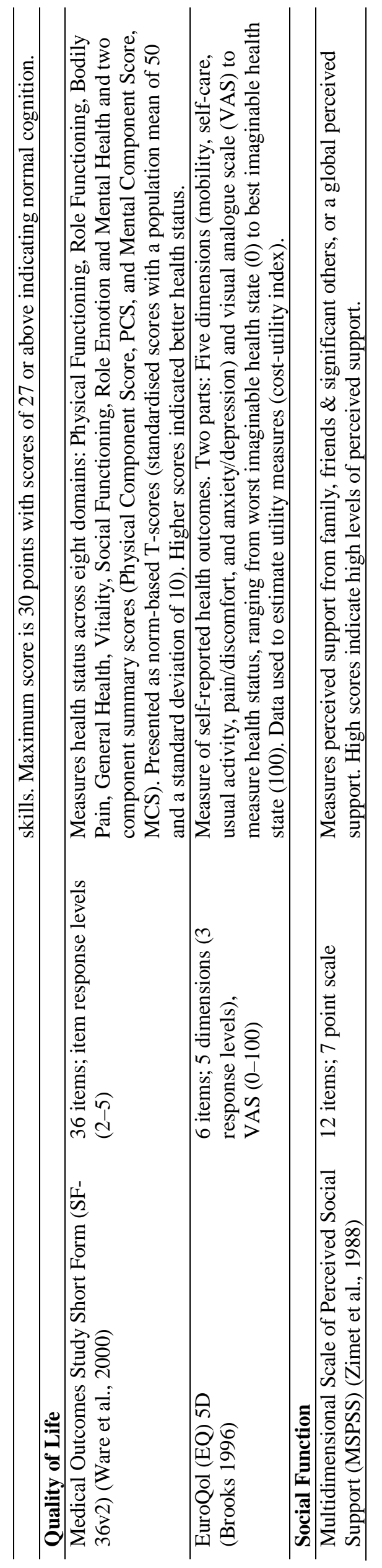




\section{References}

Aitken LM, Rattray J, Hull A, Kenardy JA, Le Brocque R and Ullman AJ. The use of diaries in psychological recovery from intensive care. Crit Care 2013;17(6):253.

Aitken LM, Williams G, Harvey M, Blot S, Kleinpell R, Labeau S, et al. Nursing considerations to complement the Surviving Sepsis Campaign guidelines. Crit Care Med 2011;39(7):1800-18.

American Thoracic Society. Guidelines for the six-minute walk test. Am J Resp Crit Care Med 2002;166:111-7.

Bailey P, Thomsen GE, Spuhler VJ, Blair R, James J, Bezdjian L, et al. Early activity is feasible and safe in respiratory failure patients. Crit Care Med 2007;35(No. 1):139-45.

Barr J, Fraser GL, Puntillo K, Ely EW, Gelinas C, Dasta JF, et al. Clinical practice guidelines for the management of pain, agitation, and delirium in adult patients in the intensive care unit. Crit Care Med 2013;41(1):263-306.

Berkius J, Engerstrom L, Orwelius L, Nordlund P, Sjoberg F, Fredrikson M, et al. A prospective longitudinal multicentre study of health related quality of life in ICU survivors with COPD. Crit Care 2013;17(5):R211.

Berney S, Haines K, Skinner EH and Denehy L. Safety and feasibility of an exercise prescription approach to rehabilitation across the continuum of care for survivors of critical illness. Phys Ther 2012;92(12):1524-35.

Bowie CR and Harvey PD. Administration and interpretation of the Trail Making Test. Nat Protoc 2006;1(5):2277-81.

Brook AD, Ahrens TS, Schaiff R, Prentice D, Sherman G, Shannon W, et al. Effect of a nursing-implemented sedation protocol on the duration of mechanical ventilation. Crit Care Med 1999;27(12):2609-15.

Brooks R. EuroQol: the current state of play. Health Policy 1996;37(1):53-72.

Btaiche IF, Chan LN, Pleva M and Kraft MD. Critical illness, gastrointestinal complications, and medication therapy during enteral feeding in critically ill adult patients. Nutr Clin Pract 2010;25(1):32-49.

Buckley T, Sunari D, Marshall A, Bartrop R, McKinley S and Tofler G. Physiological correlates of bereavement and the impact of bereavement interventions. Dialogues Clin Neurosci 2012;14(2):129-39.

Bucknall TK, Manias E and Presneill JJ. A randomized trial of protocol-directed sedation management for mechanical ventilation in an Australian intensive care unit. Crit Care Med 2008;36(5):1444-50.

Burtin C, Clerckx B, Robbeets C, Ferdinande P, Langer D, Troosters T, et al. Early exercise in critically ill patients enhances short-term functional recovery. Crit Care Med 2009;37(9):2499-505.

Buysse DJ, Reynolds CF, 3rd, Monk TH, Berman SR and Kupfer DJ. The Pittsburgh Sleep Quality Index: a new instrument for psychiatric practice and research. Psychiatry Res 1989;28(2):193-213.

Charlson ME, Pompei P, Ales KL and MacKenzie CR. A new method of classifying prognostic comorbodity in longitudinal studies: development and validation. J Chron Dis 1987;40:373-83.

Cuthbertson BH, Rattray J, Campbell MK, Gager M, Roughton S, Smith A, et al. The PRaCTICaL study of nurse led, intensive care follow-up programmes for improving long term outcomes from critical illness: a pragmatic randomised controlled trial. BMJ 2009;339:b3723.

De la Cerda G. Implementation fo an ICU follow-up clinic: outcomes and patient satisfaction after 1 year. Crit Care 2013;17(Suppl 2):S197. 
Elliott D, Denehy L, Berney S and Alison JA. Assessing physical function and activity for survivors of a critical illness: a review of instruments. Aust Crit Care 2011;24(3):155-66. Elliott D, McKinley S, Alison J, Aitken LM, King M, Leslie GD, et al. Health-related quality of life and physical recovery after a critical illness: a multi-centre randomised controlled trial of a home-based physical rehabilitation program. Crit Care 2011;15(3):R142.

Elliott R, McKinley S, Aitken LM and Hendrikz J. The effect of an algorithm-based sedation guideline on the duration of mechanical ventilation in an Australian intensive care unit. Intensive Care Med 2006;32(10):1506-14.

Fletcher SN, Kennedy DD, Ghosh IR, Misra VP, Kiff K, Coakley JH, et al. Persistent neuromuscular and neurophysiologic abnormalities in long-term survivors of prolonged critical illness. Crit Care Med 2003;31(4):1012-6.

Folstein MF, Folstein SE and McHugh PR. Mini-mental state. A practical method for grading the cognitive state of patients for the clinician. J Psychiatr Res 1975;12(3):189-98.

Fontes D, Generoso Sde V and Toulson Davisson Correia MI. Subjective global assessment: a reliable nutritional assessment tool to predict outcomes in critically ill patients. Clin Nutr 2014;33(2):291-5.

Fried LP, Tangen CM, Walston J, Newman AB, Hirsch C, Gottdiener J, et al. Frailty in older adults: evidence for a phenotype. J Gerontol A Biol Sci Med Sci 2001;56(3):M146-56.

Gosselink R, Bott J, Johnson M, Dean E, Nava S, Norrenberg M, et al. Physiotherapy for adult patients with critical illness: recommendations of the European Respiratory Society and European Society of Intensive Care Medicine Task Force on Physiotherapy for Critically Ill Patients. Intensive Care Med 2008;34(7):1188-99.

Guerin K, Wagner J, Rains K and Bessesen M. Reduction in central line-associated bloodstream infections by implementation of a postinsertion care bundle. Am J Infect Control 2010;38(6):430-3.

Hall KM, Hamilton BB, Gordon WA and Zaster ND. Characteristics and comparisons of functional assessment indices: Disability Rating Scale, Functional Independence Measure, and Functional Assessment Measure. J Head Trauma Rehabil 1993;8(2):60-74.

Hermans G, De Jonghe B, Bruyninckx F and Van den Berghe G. Interventions for preventing critical illness polyneuropathy and critical illness myopathy. Cochrane Database Syst Rev 2014;1:CD006832.

Herridge MS, Cheung AM, Tansey CM, Matte-Martyn A, Diaz-Granados N, Al-Saidi F, et al. One-year outcomes in survivors of the acute respiratory distress syndrome. $\mathrm{N}$ Eng $\mathrm{J}$ Med 2003;348(8):683-93.

Herridge MS, Tansey CM, Matte A, Tomlinson G, Diaz-Granados N, Cooper A, et al. Functional disability 5 years after acute respiratory distress syndrome. N Eng J Med 2011;364(14):1293-304.

Heyland DK, Dhaliwal R, Jiang X and Day AG. Identifying critically ill patients who benefit the most from nutrition therapy: the development and initial validation of a novel risk assessment tool. Crit Care 2011;15(6):R268.

Hofhuis JGM, Spronk PE, van Stel HF, Schrijvers GJP, Rommes JH and Bakker J. The Impact of Critical Illness on Perceived Health-Related Quality of Life During ICU Treatment, Hospital Stay, and After Hospital Discharge. A Long-term Follow-up Study. Chest 2008;133(2):377-85.

Hough CL. Improving physical function during and after critical care. Curr Opin Crit Care 2013;19(5):488-95.

Jones CP, Skirrow PM, Griffiths RDMDF, Humphris GHPMCP, Ingleby SB, Eddleston JF, et al. Rehabilitation after critical illness: A randomized, controlled trial. Crit Care Med 2003;31(10):2456-61. 
Joseph B, Pandit V, Zangbar B, Kulvatunyou N, Tang A, O'Keeffe T, et al. Validating trauma-specific frailty index for geriatric trauma patients: a prospective analysis. $\mathrm{J}$ Am Coll Surg 2014;219(1):10-7.e1.

Kaarlola A, Pettila V and Kekki P. Quality of life six years after intensive care. Intensive Care Med 2003;29(8):1294-9.

Kessler RC, Andrews G, Colpe LJ, Hiripi E, Mroczek DK, Normand SL, et al. Short screening scales to monitor population prevalences and trends in non-specific psychological distress. Psychol Med 2002;32(6):959-76.

Kiekkas P, Theodorakopoulou G, Spyratos F and Baltopoulos GI. Psychological distress and delusional memories after critical care: a literature review. Int Nurs Rev 2010;57(3):288-96.

Kress JP, Pohlman AS, O'Connor MF and Hall JB. Daily interruption of sedative infusions in critically ill patients undergoing mechanical ventilation. N Eng J Med 2000;342(20):1471-7. Lemiale V, Kentish-Barnes N, Chaize M, Aboab J, Adrie C, Annane D, et al. Health-related quality of life in family members of intensive care unit patients. J Palliat Med 2010;13(9):1131-7.

Mahoney F and Barthek D. Functional evaluation: the Barthel Index. Maryland State Medical Journal 1965;14:61-5.

McKinley S, Aitken LM, Alison JA, King M, Leslie G, Burmeister E, et al. Sleep and other factors associated with mental health and psychological distress after intensive care for critical illness. Intensive Care Med 2012;38(4):627-33.

Mehta S, Burry L, Cook D, Fergusson D, Steinberg M, Granton J, et al. Daily sedation interruption in mechanically ventilated critically ill patients cared for with a sedation protocol: a randomized controlled trial. JAMA 2012;308(19):1985-92.

Mueller C, Compher C, Ellen DM, American Society for P and Enteral Nutrition Board of D. Consensus statement of the Academy of Nutrition and Dietetics/American Society for Parenteral and Enteral Nutrition: characteristics recommended for the identification and documentation of adult malnutrition (undernutrition). JPEN J Parenter Enteral Nutr 2011;35(1):16-24.

National Institute for Health and Clinical Excellence. Rehabilitation after critical illness. NICE clinical guideline 83. Available from: http://www.nice.org.uk/CG83.2009.

Needham DM, Davidson J, Cohen H, Hopkins RO, Weinert C, Wunsch H, et al. Improving long-term outcomes after discharge from intensive care unit: report from a stakeholders' conference. Crit Care Med 2012;40(2):502-9.

Orwelius L, Nordlund A, Nordlund P, Edell-Gustafsson U and Sjoberg F. Prevalence of sleep disturbances and long-term reduced health-related quality of life after critical care: a prospective multicenter cohort study. Crit Care 2008;12(4):R97.

Pandharipande PP, Girard TD, Jackson JC, Morandi A, Thompson JL, Pun BT, et al. Longterm cognitive impairment after critical illness. N Engl J Med 2013;369(14):1306-16.

Peris A, Bonizzoli M, Iozzelli D, Migliaccio ML, Zagli G, Bacchereti A, et al. Early intraintensive care unit psychological intervention promotes recovery from post traumatic stress disorders, anxiety and depression symptoms in critically ill patients. Crit Care 2011;15(1):R41.

Peterson SJ, Tsai AA, Scala CM, Sowa DC, Sheean PM and Braunschweig CL. Adequacy of oral intake in critically ill patients 1 week after extubation. J Am Diet Assoc 2010;110(3):427-33.

Podsiadlo D and Richardson S. The timed "Up \& Go": a test of basic functional mobility for frail elderly persons. J Am Geriatr Soc 1991;39(2):142-8.

Pogorzelska M, Stone PW, Furuya EY, Perencevich EN, Larson EL, Goldmann D, et al. Impact of the ventilator bundle on ventilator-associated pneumonia in intensive care unit. Int J Qual Health Care 2011;23(5):538-44. 
Prinjha S, Field K and Rowan K. What patients think about ICU follow-up services: a qualitative study. Crit Care 2009;13(2):R46.

Pronovost P, Needham D, Berenholtz S, Sinopoli D, Chu H, Cosgrove S, et al. An intervention to decrease catheter-related bloodstream infections in the ICU. N Engl J Med 2006;355(26):2725-32.

Randolph C. Repeatable battery for the assessment of neuropsychological status (RBANS).1998 San Antonio, TX, Psychological Corporation.

Rattray J, Johnston M and Wildsmith JA. The intensive care experience: development of the ICE questionnaire. J Adv Nurs 2004;47(1):64-73.

Richards KC, O'Sullivan PS and Phillips RL. Measurement of sleep in critically ill patients. J Nurs Meas 2000;8(2):131-44.

Richmond TS, Ruzek J, Ackerson T, Wiebe DJ, Winston F and Kassam-Adams N. Predicting the future development of depression or PTSD after injury. Gen Hosp Psychiatry

2011;33(4):327-35.

Ringdal M, Plos K, Ortenwall P and Bergbom I. Memories and health-related quality of life after intensive care: a follow-up study. Crit Care Med 2010;38(1):38-44.

Rubenfeld GD. Interventions to improve long-term outcomes after critical illness. Curr Opin Crit Care 2007;13(5):476-81.

Rukstele CD and Gagnon MM. Making strides in preventing ICU-acquired weakness: involving family in early progressive mobility. Crit Care Nurs Q 2013;36(1):141-7.

Schweickert WD, Pohlman MC, Pohlman AS, Nigos C, Pawlik AJ, Esbrook CL, et al. Early physical and occupational therapy in mechanically ventilated, critically ill patients: a randomised controlled trial. Lancet 2009;373(9678):1874-82.

Singh SJ, Morgan MD, Scott S, Walters D and Hardman AE. Development of a shuttle walking test of disability in patients with chronic airways obstruction. Thorax 1992;47(12):1019-24.

Squires JE, Sullivan K, Eccles MP, Worswick J and Grimshaw JM. Are multifaceted interventions more effective than single-component interventions in changing health-care professionals' behaviours? An overview of systematic reviews. Implement Sci 2014;9:152. Tang HJ, Lin HL, Lin YH, Leung PO, Chuang YC and Lai CC. The impact of central line insertion bundle on central line-associated bloodstream infection. BMC Infect Dis 2014;14:356.

Vivodtzev I, Devost A, Saey D, Villeneuve S, Boilard G, Gagnon P, et al. Severe and early quadriceps weakness in mechanically ventilated patients. Crit Care 2014;18:431.

Ware JE, Snow KK and Kosinski M. SF-36 Health Survey: Manual and Interpretation Guide.2000 Lincoln, Quality Metric Incorporated.

Watterson C, Fraser A, Banks M, Isenring E, Miller M, Silvester C, et al. Evidence based practice guidelines for the nutritional management of malnutrition in adult patients across the continuum of care. Nutr Diet 2009;66(Supplement 3).

Weathers FW, Litz BT, Keane TM, Palmieri PA, Marx BP and Schnurr PP. The PTSD

Checklist for DSM-5 (PCL-5), National Center for PTSD at www.ptsd.va.gov.2013.

Weiss DS. The impact of event scale - Revised. Assessing psychollogical trauma and PTSD. J. P. Wilson and T. M. Keane.2004 New York, The Guilford Press.

White JV, Guenter P, Jensen G, Malone A, Schofield M, Academy of N, et al. Consensus statement of the Academy of Nutrition and Dietetics/American Society for Parenteral and Enteral Nutrition: characteristics recommended for the identification and documentation of adult malnutrition (undernutrition). J Acad Nutr Diet 2012;112(5):730-8.

Yokoe DS, Anderson DJ, Berenholtz SM, Calfee DP, Dubberke ER, Ellingson KD, et al. A Compendium of Strategies to Prevent Healthcare-Associated Infections in Acute Care Hospitals: 2014 Updates. Am J Infect Control 2014;42(8):820-8. 
Young AM, Kidston S, Banks MD, Mudge AM and Isenring EA. Malnutrition screening tools: comparison against two validated nutrition assessment methods in older medical inpatients. Nutrition 2013;29(1):101-6.

Zigmond A and Snaith R. The Hospital Anxiety and Depression Scale. Acta Psychiatrica Scandinavica 1983;67(6):361-70.

Zilberberg MD and Shorr AF. Ventilator-associated pneumonia as a model for approaching cost-effectiveness and infection prevention in the ICU. Curr Opin Infect Dis 2011;24(4):3859.

Zimet GD, Dahlen NW, Zimet SG and Farley GK. The Mulitdimensional Scale of Perceived Social Support. J Pers Assess 1988;52(1):30 - 41

Zimlichman E, Henderson D, Tamir O, Franz C, Song P, Yamin CK, et al. Health careassociated infections: a meta-analysis of costs and financial impact on the US health care system. JAMA Intern Med 2013;173(22):2039-46. 